\title{
Feedback and Its Triangulation with Teaching and Learning: A Quality Enhancement Strategy.
}

\author{
Dr. Andrew Chindanya \\ Department of Teacher Development: Great Zimbabwe University
}

\begin{abstract}
Although feedback is one of the most powerful influences on learning and achievement, its impact can be either positive or negative. This research focused on how feedback could be employed as a quality enhancement strategy in the teaching and learning process at university level. A qualitative case study involving a total of sixty students on three different programmes, namely: Bachelor of Education II (all ten students), Bachelor of Education III (all twenty students) Bachelor of Education IV (all 30 students) was carried out. All students on the said programmes participated in the study which collected data using focus group interviews and document analysis. Findings indicated that students valued feedback as it reassured them in terms of their progress. It had motivational potency. The feedback needed to be timely and varied, focusing not only on a task, but also on the process used to complete a task. It further emerged from the findings that feedback should be a symbiotic process benefiting both the student and the lecturer. When the two parties got feedback from each other the teaching and learning process was enhanced. The evidence also revealed that the type of feedback and the way it was given could be differentially effective. The study suggests ways in which feedback could be used to enhance effective teaching and learning.
\end{abstract}

\section{Introduction}

Feedback has often been described as the educational process of giving and taking (Gibbs, Brigden and Hellenberg, 2006). In other words, the lecturer gives and receives feedback to and from the student and the student also gives and gets feedback to and from the lecturer. The lecturer enhances his/her performance in consequence of the feedback he/she gets from students. Equally true, the student enhances his/her performance in consequence of the feedback he/she gets from the lecturer. It is now common knowledge that feedback is one of the most significant factors in terms of enhanced performance.

Feedback can be viewed as information and advice provided by a lecturer about a learner's performance or information and advice provided by a learner about a lecturer's performance in order to improve performance. In the words of Ramaprasad (1983), "Feedback is a process in which information about the past or the present influences the same phenomenon in the present or future". Feedback should indicate the degree to which a goal or expectation is left unmet. Such information allows learners to check and improve the quality of their understanding, their application of knowledge and skills and the processes by which they acquire new capabilities. Equally true, the information must enable lecturers to see the gaps in their teaching so as to improve on their performance. This is so because the feedback information relates to the correctness, accuracy, or appropriateness of the recipient's past performance.

Students value feedback since it is reassuring as an indication of their progress (Williams and Kane, 2009). They believe that it helps them to improve before the next assignment. That is why they are concerned with the quality of the feedback. Skimpy comments do not constitute valuable feedback and are not regarded as meaningful feedback by students.

In relation to feedback lecturers receive from students, feedback can also be regarded as "...the expressed opinions of students about the service they receive as students" (Harvey, 2001:2, in Pearn, 2004). The opinions are also meant to help the lecturer to see where and how he/she needs to improve his/her performance. The feedback can motivate the lecturer to work in a manner beneficial to students.

Feedback occurs during lecture-room activities or following a student's response to a lecture-room activity or assessment of an assignment or project. It can be spoken, non-verbal, formal, informal or written.

It is self-evident from the foregoing that feedback is central to teaching and learning. If given properly, it enhances teaching and learning. However, if given improperly, it has the potential to be harmful to the recipient.

\section{Theoretical framework}

The Attribution theory was used to explain some of the comments made by both lecturers and students regarding each other's comments. It was also used to generate solutions to the problem under study. 
Lecturers and students attribute success and failure to different things. They give different reasons why a student has failed or accomplished a task or performance. Success attracts attributions of high ability, a lot of effort, easy tasks or luck. Conversely, failure attracts attributions of low ability, little effort, difficult tasks or no luck. Ability attributions are internal, stable and uncontrollable while effort attributions are internal, unstable and controllable (Simmering 2011:1).

When failure is attributed to internal, uncontrollable and stable causes such as low ability, it is interpreted as a consequence of a fixed characteristic over which an individual has no control . Having no control predisposes one to feelings of hopelessness and expectations of continued failure (Haack 2007:48). It makes one feel shame and humiliation. It also renders one reluctant to expend effort or to be persistent in terms of future tasks.

When failure is attributed to internal, unstable and controllable causes (such as lack of effort) it is considered redeemable since one can do something about it. Having control stimulates feelings of hopefulness in relation to future outcomes. Attributing success to internal and controllable factors such as effort, kindles feelings of pride, satisfaction and confidence. It also generates a sense of self esteem. Consequently one is inclined to initiate achievement activities, choose to work on more difficult tasks, persist longer in the face of failure and expend greater energy in tackling difficult tasks.

Attributing success to external forces such as task difficulty will not engender self -enhancing emotions such as satisfaction, pride, confidence or self esteem.

\section{Context/what inspired the research}

This research was inspired by comments made by students on lecturer effectiveness (reflected in the lecturer appraisal form). Typical comments on the remarks lecturers made on students' written assignments included the following:

- "too judgemental"

- "makes useless comments"

- "makes general comments"

- "makes humiliating comments"

- "makes discouraging comments"

- "lazy, takes too long to mark our work"

According to the students, such comments were common and tended to depress their enthusiasm to learn. This provoked in the mind of the researcher such questions as: Was feedback receiving due attention at the university? Were lecturers competent to give useful feedback? Were lecturers aware of what feedback entailed?

Students' remarks on lecturers' comments relating to their performance provoked interest to also establish what lecturers thought about students' feedback on their teaching. Such feedback came through performance appraisal forms which students filled in, students' responses during lecturing episodes and students' general attitude towards a lecturer. The typical comments of lecturers regarding students' feedback included such words as "trivial", "not serious", "mocking", "irresponsible", "useless", "disrespectful", "frivolous", "insulting". The comments were consistent with Richardson's (2005) observation that students' evaluation of teaching often tended to be a ritual not always regarded as a serious matter by those involved. Such comments also inspired the researcher to seek to establish whether students and lecturers fully appreciated what feedback entailed and whether such an appreciation made them competent in dispensing feedback.

From the remarks of both lecturers and students the researcher sensed that although feedback was indispensible in teaching and learning, it could have very adverse effects if not properly handled. This research therefore sought to establish how feedback could be utilised to enhance teaching and learning. In the process of doing so, the study gave some focus on what lecturers and students regarded as the purpose of feedback, how they experienced feedback from each other, and how feedback could be made effective.

\section{Methodology}

The primary intent of the study was to establish how feedback could be used as a strategy to enhance teaching and learning. The qualitative research methodology was used because it derives meaning from research participants' perspective. Since feedback is more effective if it is tailor-made to suit the recipients' needs, it was important to establish what feedback recipients perceived as useful/helpful feedback. Attribution theory was used to illuminate lecturers' and students' attitude to certain types of feedback

\subsection{Selection of respondents}

A total of sixty students on three degree programmes were chosen as follows: all thirty Bachelor of Education Part Four pre-service students, all twenty Bachelor of Education Part Three pre-service students and all ten Bachelor of Education Part Two pre-service students. All twenty two lecturers who taught the three 
programmes were involved in the study. It was decided to include all students and lecturers involved with the three programmes selected since the numbers of the participants were not too large to warrant sampling.

\subsection{Data collection strategies}

The following data collection strategies were used: document analysis, focus group interviews and a semi-structured questionnaire. The documents that were analysed were staff appraisal forms filled in by students. Focus group interviews were conducted to get the views of both lecturers and students, so was the semi-structured questionnaire.

$$
\text { - }
$$

\section{Findings}

In spite of its incontestable significance, feedback remains a vexed issue in universities. The findings presented and discussed below confirm that both students and lecturers had some awareness of what feedback entailed and yet they often failed, when dispensing it, to give it the attention it deserved. The findings are discussed under the themes that emerged from the research.

\subsection{Understanding of the concept feedback.}

It emerged from both students' and lecturers' responses that they understood feedback to be, basically, communication from the lecturer to the student indicating to the student strengths and weaknesses surrounding a performance, and vice versa. A typical response from students and lecturers who saw feedback from the perspectives of both students and lecturers was:

"Feedback means information from a lecturer to a student, or from a student to a lecturer, pointing out weaknesses and strengths in relation to a performance with the view to improving performance.”

Such an archetypal response confirmed that students and lecturers were aware of what feedback entailed. It was rather puzzling, therefore, that students and lecturers were not meticulous when dispensing it. Perhaps it is in this context that Richardson (2005) remarks that unless students see that the expression of their opinions leads to concrete changes in teaching practices, they would regard feedback as no more than a ritual they go through for no apparent reason. Students feedback must therefore be taken seriously by lecturers and institutions.

\subsection{The significance of feedback from the students' perspective}

According to the students, good feedback enabled them to evaluate their performance for future improvement. Typical responses in this respect were:

"Good feedback helps me to see where and how I went wrong so that I can perform better in subsequent efforts";

"I expect feedback to guide me on how to proceed with my studies"; and

"Feedback should be motivational...confirming my strengths and indicating my weaknesses in a manner that shows me how to overcome the weaknesses".

Students' comments indicated that they had a general appreciation of the importance of feedback in relation to their work. They saw it as meant to reduce the discrepancy between current and desired understanding. The literature confirms the significance of feedback to students. According to Williams and Kane (2009), feedback was valued by students as an indication of progress. They saw it as helping them to improve before the next assignment. This is why they were concerned principally about the amount of time taken by lecturers to return their work and with the quality of comment provided (Williams and Kane, 2009).

With regards to how the feedback they gave lecturers was important, students said the feedback was expected to make lecturers aware of weaknesses in their performance so that they addressed such weaknesses and improved future performance. Responses that typified such students' thinking were:

"Feedback is supposed to enable lecturers to identify their strengths and weaknesses so that they enhance their performance for our benefit";

"It should help the lecturers to confirm or disconfirm whether they are reaching the students."

It emerged from such comments that students were aware of the importance of the feedback they were supposed to give their lecturers. Asked why they were not meticulous when dispensing it, they indicated that they often thought that lecturers did not give their comments the attention they deserved. Once they were convinced that lecturers would take their feedback comments seriously, they thought they were competent to give feedback more seriously.

\subsection{The significance of feedback from the lecturers' perspective}

Lecturers thought that good feedback helped them to improve their practice. Typical answers were:

"Good feedback helps me to improve on strategies and methods of lecture delivery"; 
"It enables me to decide whether to continue using the same lecture notes or change them";

"It helps me to know the effectiveness of my performance so that I may improve if need be", and

"It helps me to know the learning needs of my students so that I strategise to meet these needs."

Lecturers indicated that they were prepared to take students' comments (feedback) seriously once students made them seriously. There was need therefore to encourage students to meaningfully give feedback to their lecturers so as to derive substantial benefits from it. The language they use should not be denigrating, neither should it be reckless.

\subsection{Modes of feedback}

Both students and lecturers indicated that feedback came in various forms that included verbal comments, written comments combined with marks, comments on class presentations, action and gestures, test or examination results, students' attitude towards the lecturer, student appraisal forms and peer evaluation forms. So feedback could be written, spoken, or non-verbal. It occurred during lecture room activities or following a student's response to a classroom activity or assessment. Whatever form it came, positive feedback was important in enhancing performance.

Both students and lecturers were aware of the various ways in which feedback occurred. They needed to be alert to its occurrence both during lecture time and after lecture time so as to timely respond to it. Lecturers and students had different preferences of the modes of feedback but most of them showed largely similar preferences.

\subsection{The most useful forms of feedback according to students}

According to students, the most useful forms of feedback are the following, in descending order, that is, the most mentioned by participants first and the least mentioned last: informative written comments combined with marks ("When written comments are combined with marks, feedback value is enhanced"); informative written comments ("Informative written comments are very useful because one can always refer back to the written comments for guidance); informative verbal comments ("If given in a supportive, and not in a condemning or condescending manner, verbal comment is also quite useful"); focusing actions and gestures ("Actions and gestures during a lecture or learning episode are an underestimated form of feedback”).

From the students' responses it is clear that students expect feedback to help them to determine whether they were on the right track, what their strengths were, what their weaknesses were, how they were doing overall and how they could make improvement.

The students' answers also indicated that effective feedback was that which provided cues or reinforcements to learners. Sadler (1989) in Hattie and Timperly (2007) affirms that to have instructional value, feedback needs to provide information that specifically relates to the task or process of learning that fills the gap between what is understood and what is aimed to be understood.

\subsection{The least useful forms of feedback}

The following were cited as the least helpful forms of feedback: test or examination results ("Examination results are a form of feedback that's important but comes rather late"); and marks on their own ("Marks on their own are important to a rather limited extent since they really do not indicate the direction one has to take following a sub- standard performance").

In relation to timeliness, Hattie and Timperley (2007) affirm that feedback is meant to reduce the discrepancy between current and desired understanding. If it comes late, it follows, students do not derive optimal benefit from it.

In relation to a mark or a grade on its own, Williams and Kane (2009) posit that without written comments on their performance, students remain unaware of the significance of the mark or why it may be different from previous marks. Marks accompanied with constructive comments are likely to have motivational and instructive value.

\subsection{How students wanted to be given feedback}

Students wanted to be given feedback as follows: promptly; informatively enough to enable them to correct themselves or to improve in the succeeding performance; decently enough for them to preserve their dignity and self-esteem; in a motivating manner.

With respect to the need for promptness in giving feedback, students typically said: "Giving us feedback late diminishes the value of the feedback...it's as simple as that." or "Feedback delayed is feedback denied." Students were clearly irritated by delayed feedback. Their responses suggested that they lost interest if feedback was delayed. This impacted negatively on their motivation. The literature confirms that students are concerned with the promptness of feedback (Williams and Kane, 2009). Hatziapostolou and Paraskakis (2010) 
give timeliness as a condition of feedback effectiveness (Hyland, 2000). In the words of Gibbs (2006 b), “...if feedback is provided faster, there is more likelihood that students will read and respond to it." They need it to improve their performance. Thus they have an expectation of meaningful comment on their work.

In terms of feedback having to be sufficiently informative to enable students to improve in succeeding performance, students characteristically answered as follows: "The marked assignment should have both intext comments and summative comments", and "Feedback should be detailed enough to help me improve my performance." Students' comments suggest that they expected more detailed comments from lecturers, although a minority seemed unconcerned about comprehensive comments. Williams and Kane (2009) also found that most students were frustrated by skimpy comments. They were concerned with the quality of the comments.

With regards to the need for feedback to be decent enough to allow the students to retain their dignity, the typical response was: "I for one want feedback that is respectful, confidential, helpful and encouraging" or "I prefer feedback that stimulates my desire to excel in my performance... feedback that makes me feel good about myself”) or "I resent feedback that's belittling or demeaning."

\subsection{How students did not want to receive feedback}

Students did not want to receive feedback presented as follows: open verbal criticism from the lecturer; condemnatory or condescending written comments; when the mark and comments did not tally; delayed feedback; when it focused on a person rather than on performance (I prefer feedback to focus on my performance rather than on me...the lecturer may make wrong assumptions about me and comment in a manner that would offend me.) ; when lecturers wrongly attribute students' performance (As a student, I don't respect or trust a lecturer who wrongly attributes my performance"); when given out of context; when given as a "one-cap-fits-all" comment that is not tailored to an individual's effort ("Some lecturers make vague feedback thus rendering it ineffective", "Some lecturers make general comments that are scarcely linked to learning objectives...I think that's being dishonest... Students tend to be inattentive to generalised comments ".

Goodwin and Miller (2012) confirm that vague feedback can have negative effects on students, resulting in uncertainty, decreased motivation, and even "diminished learning".

From the foregoing, it is apparent that students respond positively to feedback that is helpful, respectful, confidential and encouraging. Such productive feedback stimulates students' desire to excel in their performance.

\section{Recommendations}

University departments of teacher education or teacher development should run courses that touch on feedback for lecturers who do not hold teaching qualifications or have limited teaching experience. Staff development workshops should be mounted to enlighten lecturers with regards to productive feedback.

Lecturers need to:

- give feedback at the right time;

- make feedback targeted and specific;

- set realistic goals for students;

- link feedback to learning objectives;

- make feedback helpful by indicating missing gaps and suggesting ways to fill them in order to achieve the objective;

- make feedback, respectful confidential and encouraging;

- $\quad$ set a climate of trust and respect;

- avoid wrongly attributing students' performance;

- clarify expectations of performance; and

- focus on performance rather than on the student.

Students need to:

- give feedback respectfully;

- be specific;

- be honest; and

- indicate suggestions to improve performance.

VII. Limitations and future directions

The study was limited to only three programmes from one faculty because of time constraints. Further research should involve more faculties. 


\section{Conclusion}

While feedback is recognised as critical to teaching and learning at university level, it is a matter of concern that it seemingly is not receiving the attention it deserves. Yet, when dispensed competently, feedback can be a very effective quality enhancement tool for both teaching and learning.

\section{Reference List}

[1]. Gibbs, T., Brigden,D., and Hellenberg, D. 2006. Feedback: The Educational Process of Giving and Receiving. SA Fam Prat.2006, 48 (2).

[2]. Goodwin, B. and Miller, K. 2012. Feedback for Learning. Educational Leadership. Volume70, Number 1, pp 82-83

[3]. Haack, M.K. 2007. Parents' and Teachers' Beliefs about Parental Involvement in Schooling. Unpublished PhD Thesis. University of Nebraska.

[4]. Hattie, J. and Timperly, T. 2007. The power of feedback. Review of Educational Research. Hatziapostolou, T. and Paraskakis, I. (2010). Enhancing the impact of Formative Feedback on Student Learning through an Online Feedback System. Electronic Journal of E-learning. Volume 8, Issue 2, 2010, pp 111-122, available online at www.ejel.org

[5]. Irons, A. 2008. Enhancing learning through formative assessment, Routledge: London. Juwah, C., Macfarlane-Dick, D., Mathew, B., Nicol, D., and Smith, B. 2004. Enhancing Student Learning through Effective Formative feedback, The Higher Education Academy, [Online], http://www.heacademy.ac.uk/assets/York/documents/resources/resourcedatabase/id353_senlef_guide.pdf

[6]. Pearn, S.M. Collecting and responding to postgraduate student feedback: the experience of the University of Bristol. PERSPECTIVES, Volume 8, Number 3, pp 74-80 Race, 2006

[7]. Ramaprasad, A. 1983. On definition of feedback. Behavioural Science, Vol. 28, 1, 1983

[8]. Richardson, J.T.E. 2005. Instruments for obtaining student feedback: a review of the literature. Assessment and Evaluation in Higher Education. Vol.30, Number 4, August 2005, 2005, pp 387-415.

[9]. Shute, V. J. 2008. Focus on formative feedback. Review of Educational Research, 78(1), 153 - 189.

[10]. Simmering, M.J. 201. Encyclopedia of Educational Management.eNotes.com, Inc. Retrieved on 20 August, 2011 from http://www.enotes.com/management-encyclopedia/attribution-theory

[11]. Williams, J. and Kane, D. 2009. Assessment and Feedback: Institutional experiences of Student feedback,1996 to2007. Higher Education Quarterly. Volume 63, No. 3, July 2009, pp 264-286. 